\title{
Strategies for construction of the all-carbon macrocyclic skeleton of the ansamycin antibiotic-kendomycin
}

\author{
Shu $\mathrm{Xu}^{1,2}$ and Hirokazu Arimoto ${ }^{3}$ \\ Kendomycin, an ansamycin-type natural product first reported in 1996, possesses a series of attractive bioactivities and a \\ unique all-carbon macrocyclic skeleton. To the date, seven total syntheses, two formal total syntheses and a number of synthetic \\ studies on this hot molecule have been reported. In this short review article, we mainly survey and comment on these efforts \\ regarding the difficult macrocyclization strategies.
}

The Journal of Antibiotics (2016) 69, 203-212; doi:10.1038/ja.2016.5; published online 10 February 2016

\section{INTRODUCTION}

Kendomycin $[(-)-T A N 2162,1]$ is a secondary metabolite isolated from Streptomyces species. It was first reported in 1996 by Takeda Pharmaceutical Co. Ltd, Osaka, Japan (identification of the planar structure) as an antagonist for an endothelin receptor from Streptomyces AL-71389, ${ }^{1,2}$ and later in 1998 by Su et al. ${ }^{3}$ (ascertainment of the relative stereochemistry) as an antiosteoporotic agent from Streptomyces NRRL-21370. In 2000, Bode and Zeeck ${ }^{4}$ re-isolated this compound from Streptomyces violaceoruber 3844-33C and identified its absolute configuration by the advanced Mosher's ester method. The authors reported its cytotoxic effects on three human tumor cell lines in addition to its remarkable antibacterial activity against both Grampositive and Gram-negative bacteria, notably the STA MU50 strain, which belongs to not only methicillin-resistant Staphylococcus aureus but also vancomycin-intermediate Staphylococcus aureus strains. Further biological studies showed that its cytotoxicity may be derived from proteasome inhibition ${ }^{5,6}$ and Bcl-xl inhibition. ${ }^{7}$

Structurally, kendomycin (1, Figure 1) belongs to the ansamycin family and contains a cyclophane framework. It comprises a quinone methide chromophore set in the macrocycle, which was heavily assembled with stereogenic centers particularly on the tetrahydropyran segment. Notably, distinguished from the macrolactam connection of usual ansamycins, the aliphatic ansa-chain of 1 connects to the chromophore via carbon-carbon bonds.

The biosynthetic pathway of 1 was disclosed first by Bode and Zeeck, $^{4,8}$ and further by Müller and co-workers ${ }^{9}$ (Scheme 1). It was proposed that the ansa-chain is added onto the benzoic acid 2 or its benzoquinone derivative 3 with a type-I polyketide synthase assembly line. The generated 4 undergoes a pyran-cyclization to form $\mathbf{5}$, which further forms the macrocarbocyclic intermediate 6 through aldol condensation between the malonate terminus and the quinone carbonyl. Finally, dehydration and hemiacetal formation furnish $\mathbf{1}$. The biogenetic studies provided informative hints for the design of chemical syntheses.

The combination of attractive bioactivities and the unique chemical structure of kendomycin (1) has been of great interests to the synthetic and medicinal communities. To date, seven total syntheses, two formal total syntheses, and a number of synthetic efforts have been published.

The key points that should be overcome in the total synthesis of 1 are the following: (I) efficient macrocyclization, (II) selective installation of the multiple stereogenic centers and (III) construction of the sensitive quinone-methide-lactol moiety. For point (III), all of the reported synthetic strategies left this difficult task for the last steps of the total synthesis. Though the syntheses reported by most research groups have suffered from this painful transformation, we think that this obstacle has basically been surmounted through the efforts in many laboratories. For point (II), the proposed biosynthetic pathways and a varieties of synthetic examples from other macrocyclic natural products suggest that it is much easier to install the multiple stereogenic centers before the macrocyclization step. Fortunately, owing to the rapid development of the asymmetric synthesis field, more reliable protocols (especially reagent-controlled protocols) reduce the difficulties associated with point (II) in total synthesis research, though trials are still needed to find the most efficient way. Therefore, points (II) and (III) have not been the major problem for total synthesis of 1 . Efficient cyclization of the 18-membered carbocycle, point (I), is still the primary challenge for further synthetic studies on this hot molecule and its structure-activity relationship research.

\footnotetext{
${ }^{1}$ State Key Laboratory of Bioactive Substance and Function of Natural Medicines, Institute of Materia Medica, Chinese Academy of Medical Sciences and Peking Union Medical College, Beijing, China; ${ }^{2}$ Department of Medicinal Chemistry, Beijing Key Laboratory of Active Substances Discovery and Drugability Evaluation, Institute of Materia Medica, Peking Union Medical College and Chinese Academy of Medical Sciences, Beijing, China and ${ }^{3}$ Graduate School of Life Sciences, Tohoku University, Sendai, Japan Correspondence: Professor H Arimoto, Graduate School of Life Sciences, Tohoku University, 2-1-1 Katahira, Sendai 980-8577, Japan.

E-mail: arimoto@biochem.tohoku.ac.jp

Received 27 November 2015; revised 9 January 2016; accepted 15 January 2016; published online 10 February 2016
} 


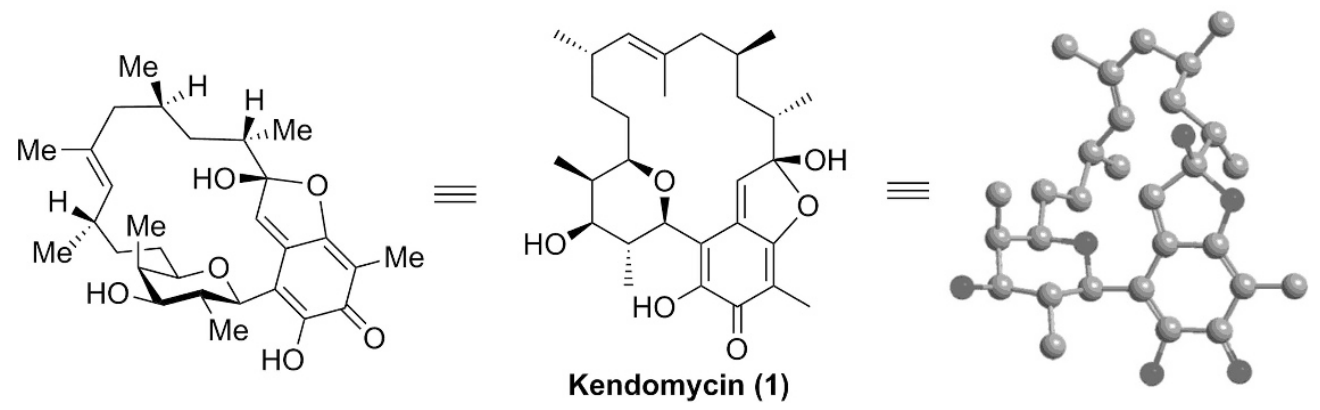

Figure 1 The structure of kendomycin (1). Me, methyl.<smiles>Cc1c(O)c(O)c(C(=O)O)c(O)c1O</smiles><smiles>CC1=C(O)C(=O)C(C(=O)O)=C(O)C1=O</smiles><smiles>CCCCC(=O)CC(=O)C(C)CC(C)CC(C)=C[C@@H](C)CCC(O)[C@@H](C)[C@@H](O)C(C)=CC1=C(O)C(=O)C(C)=C(O)C1=O</smiles><smiles>CCOC(=O)CC(=O)C(C)CC(C)CC(C)=CC(C)CCC1OC(C2=C(O)C(=O)C(C)=C(O)C2=O)C(C)C(O)C1C</smiles><smiles>CC(=CC(C)CCC1OC(C2=C(O)C(=O)C(C)=C(O)C2(O)CC(=O)O)C(C)C(O)C1C)CC(C)CC(C)CC(C)C</smiles>

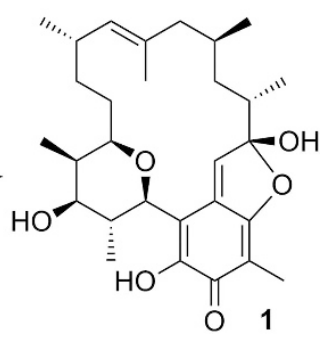

Scheme 1 The proposed biosynthetic pathway of kendomycin (1). PKS, polyketide synthase.

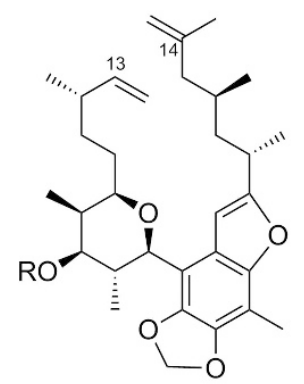

$7 \mathrm{R}=\mathrm{H}$

$8 \mathrm{R}=\mathrm{Ac}$

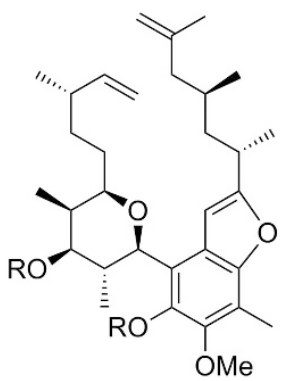

$9 \mathrm{R}=\mathrm{H}$

$10 \mathrm{R}=\mathrm{Ac}$

$11 \mathrm{R}=\mathrm{MOM}$

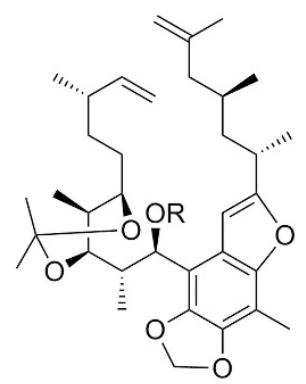

$12 \mathrm{R}=\mathrm{H}$

$13 \mathrm{R}=\mathrm{Ac}$

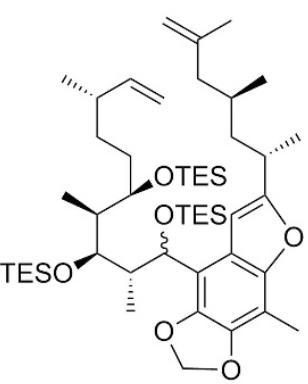

14

Grubbs II or Schrock catalysts various conditions

no cyclization products detected

Scheme 2 Mulzer group's initial failed attempts for macrocyclization at C13-C14 by ring-closing metathesis (RCM). Ac, acetyl; MOM, methoxymethyl; TES, triethylsilyl.

Several review articles have been published that summarize the synthetic efforts toward 1, including two early-period comprehensive reviews, ${ }^{10,11}$ two personal accounts, ${ }^{12,13}$ and one specific review on the olefin metathesis strategy. ${ }^{14}$ In this short review, we will provide a survey and discussion on the macrocyclization strategies (both successful and failed) reported so far in the synthetic studies of 1 .

\section{CHRONOLOGICAL EFFORTS OF THE MACROCYCLIZATION} STRATEGIES FOR KENDOMYCIN

The pioneer trial for the construction of the macrocycle of kendomycin (1) was first reported by Mulzer et al. ${ }^{15}$ They attempted to connect the $\mathrm{C} 13-\mathrm{C} 14$ double bond by ring-closing olefin metathesis (RCM) based on a series of benzofuran substrates 7-14 (Scheme 2). ${ }^{12,16-19}$ However, none of the substrates produced 

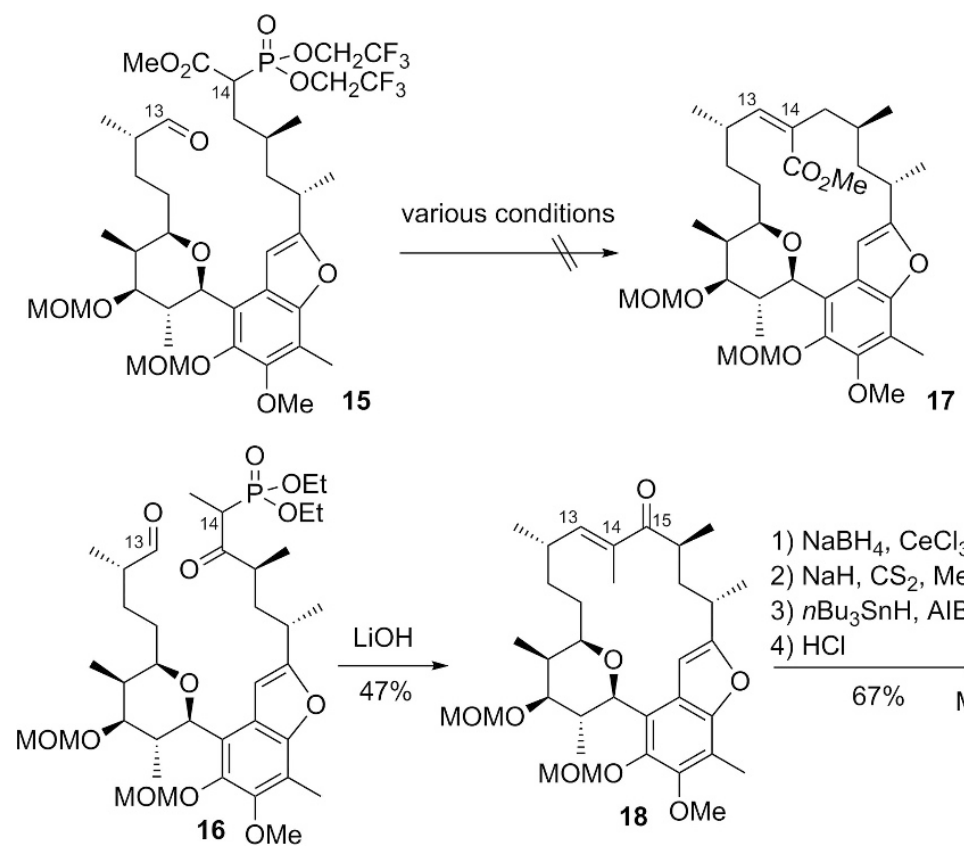

1) $\mathrm{NaBH}_{4}, \mathrm{CeCl}_{3}$

2) $\mathrm{NaH}, \mathrm{CS}_{2}, \mathrm{Mel}$

3) $n \mathrm{Bu}_{3} \mathrm{SnH}, \mathrm{AIBN}$

4) $\mathrm{HCl}$

$67 \%$

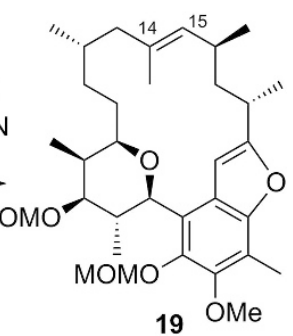

Scheme 3 The Mulzer group's attempts for macrocyclization at C13-C14 by Horner-Wadsworth-Emmons (HWE) reaction. AlBN, azobisisobutyronitrile; $\mathrm{Bu}$, butyl; Et, ethyl.
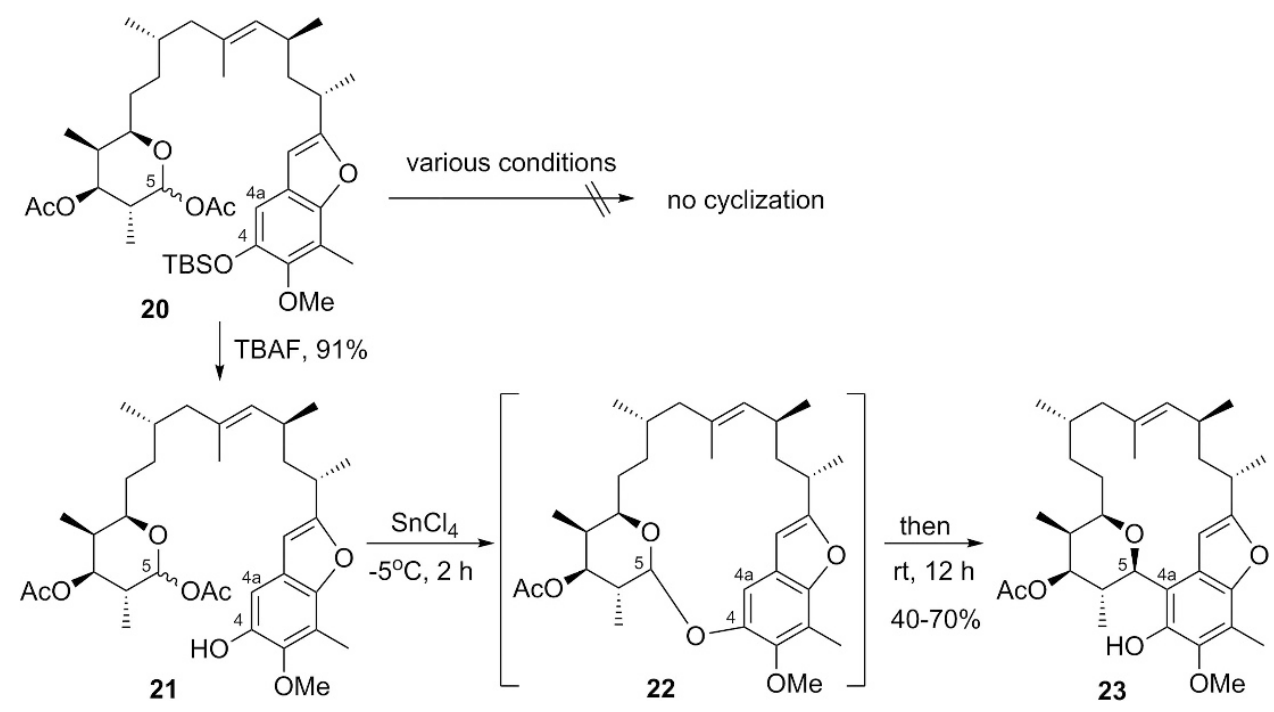

Scheme 4 The Lee group's diastereoselective macrocyclization by C-glycosidation between C4a and C5. h, hour; rt, room temperature; TBAF, tetrabutylammonium fluoride; TBS, tert-butyldimethylsilyl.

macrocyclic products under various conditions with Grubbs 2ndgeneration catalyst or Schrock catalyst. The byproducts were thought to mainly be dimers and oligomers. They rationalized that the planar benzofuran system might cause the two olefin terminuses to not be spatially near enough for the intramolecular reaction.

Another strategy that Mulzer, Martin and co-workers tried for the C13-C14 connection was through the Horner-Wadsworth-Emmons reaction (Scheme 3). ${ }^{15}$ Two substrates $\mathbf{1 5}$ and $\mathbf{1 6}$ were prepared. While compound 15 failed to provide the desired cyclization product 17 under various conditions, compound $\mathbf{1 6}$ did macrocyclize to afford 18. The subsequent task was the removal of the $\mathrm{C} 15$ carbonyl. However, it resisted direct reduction, and a two-step procedure using Luche reduction and Barton-McCombie deoxygenation led to a double-bond migrated undesired product 19, possibly via [3,3]-sigmatropic rearrangement ${ }^{12,15}$ or allyl radical rearrangement. ${ }^{11}$ Therefore, though the Horner-Wadsworth-Emmons strategy succeeded in the macrocyclization step, it unfortunately could not lead to the final target $\mathbf{1}$.

In 2004, Lee and co-workers achieved the first total synthesis of kendomycin (1) by talentedly using a $C$-glycosidation for the macrocyclization (Scheme 4). ${ }^{20}$ While their initial cyclization attempt failed on tert-butyldimethylsilyl (TBS)-protected phenol 20 under various conditions (no cyclization product, mainly hydrolysis of the anomeric acetate), the macrocyclization proceeded smoothly using the TBS-deprotected free phenol 21 with Lewis acid $\mathrm{SnCl}_{4}$. At $-5^{\circ} \mathrm{C}$ the $\mathrm{O}$-glycosidation product $\mathbf{2 2}$ was possibly afforded and then rearranged to the $C$-glycosidation product $\mathbf{2 3}$ at room temperature. Notably, the 


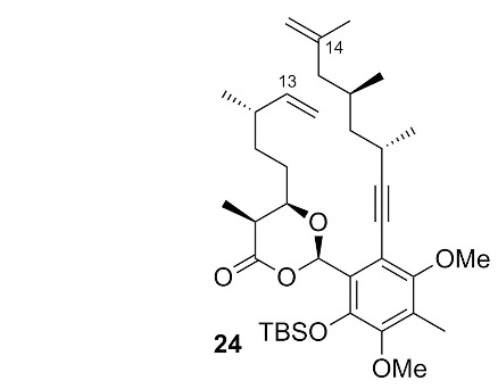<smiles>C=C[C@H](C)CC[C@H](C)C[C@@H](C)C#Cc1c(OC)c(C)c(OC)c(OC(C)(C)C)c1[C@H]1CC(=O)[C@H](C)[C@@H](CC(=C)C)O1</smiles>

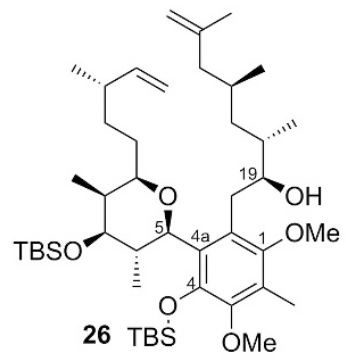

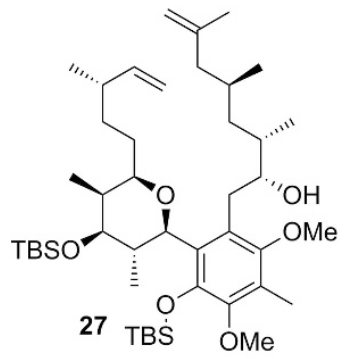

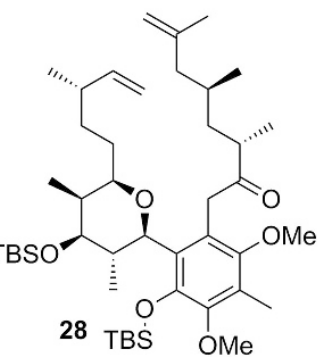<smiles>C=C[C@H](C)CCC1O[C@H](c2c(O)c(OC)c(C)c(OC)c2C[C@H](O)[C@H](C)C[C@H](C)CC(=C)C)[C@H](C)[C@H](OC(C)C)[C@@H]1C</smiles><smiles>C=C[C@H](C)CCC1O[C@H](c2c(O)c(OC)c(C)c(OC)c2C[C@H](O)[C@@H](C)C[C@@H](C)CC(=C)C)[C@H](C)[C@H](OC(C)(C)C)[C@@H]1C</smiles>

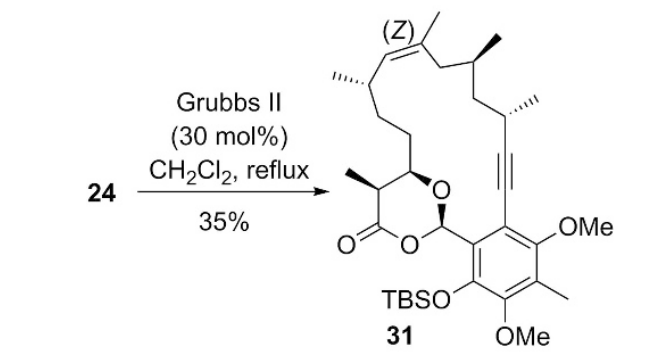

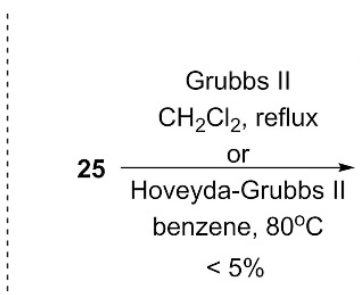<smiles>COc1c(C)c(OC)c(OC(C)(C)C)c(C2CC(=O)[C@H](C)[C@H](CC[C@@H](C)/C=C(\C)C[C@@H](C)C[C@H](C)C#CC(C)(C)C)O2)c1OC</smiles>

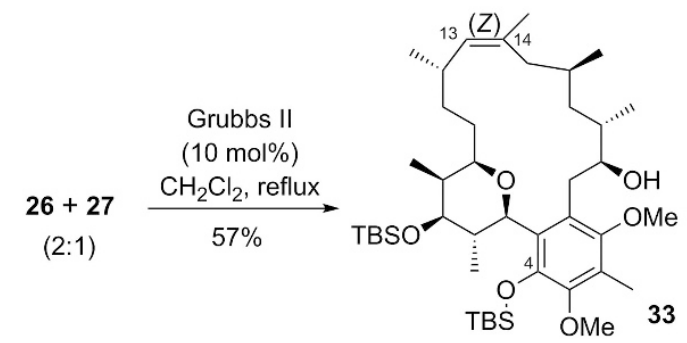
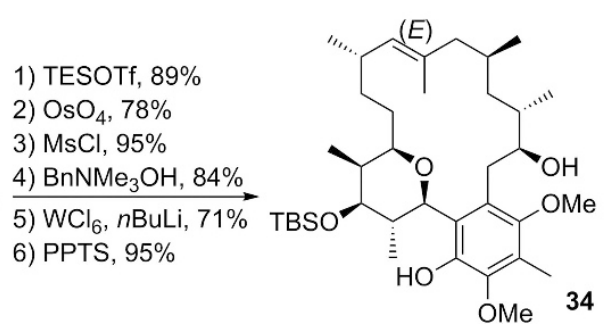

Scheme 5 Smith's macrocyclization by RCM between $\mathrm{C} 13$ and $\mathrm{C} 14 . \mathrm{Bn}$, benzyl; Ms, methanesulfonyl; PPTS, pyridinium p-toluenesulfonate; Tf, trifluoromethanesulfonyl.<smiles>C=C[C@H](C)CCC1O[C@H](c2c(CC(=O)/C(C)=C/[C@H](C)CC(=C)C)c(OC)c([13CH3])c(OC)c2OC)[C@H](C)[C@@H](OC(C)(C)C)[C@@H]1C</smiles>

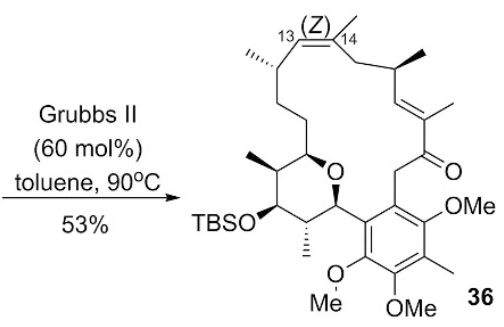

Scheme 6 The Arimoto group's macrocyclization using RCM between $\mathrm{C} 13$ and C14.

cyclization process was highly selective, providing only the single desired diastereomer, though with modest unstable yield (40-70\%). Subsequently, three steps completed the asymmetric total synthesis of kendomycin (1).

The second total synthesis of $\mathbf{1}$ was reported by Smith et al. in 2005. ${ }^{21,22}$ While the Mulzer group failed with the benzofuran-type substrates (vide supra), ${ }^{15}$ the Smith group continued challenging the RCM strategy at the C13-C14 double bond with furan-ring-opened substrates (Scheme 5). In a series of seven prepared substrates, compounds 24, 25 and 26 provided the macrocyclic RCM products, while 27 (C19 epimer of 26), 28 (C19 ketone analog of 26), 29 (C4-OH of 26) and 30 (C4-OH of 27) failed. The RCM reactions of 24-26 were highly selective, affording only one isomer, though with the undesired $Z$-geometry (for 25 , the product geometry could not be determined). The best yield was obtained from 26 to macrocycle 33 (57\% from 2:1 epimer mixture of $\mathbf{2 6}$ and $\mathbf{2 7}$ or $86 \%$ calculated for $\mathbf{2 6}$ only). Though not completely understanding the RCM reactivity difference for the substrates with only subtle changes, the Smith group proposed that in compound 26, the opened furan ring, the hydrogen bonding between $\mathrm{C} 19-\mathrm{OH}$ and $\mathrm{C} 1-\mathrm{OMe}$, and the bulky TBSO at $\mathrm{C} 4$ (fixing the $\mathrm{C} 4 \mathrm{a}-\mathrm{C} 5$ rotamer) should together contribute greatly to the conformation of the cyclization transition state. Several extra steps were necessary to isomerize the double bond geometry from 33 to 34 , which was subsequently transformed to kendomycin (1). 
Arimoto and co-workers also reported their attempts for the RCM macrocyclization between $\mathrm{C} 13$ and C14 (Scheme 6). ${ }^{23,24}$ With compound 35 having a more rigid right chain compared to Smith's intermediate 26, the macrocyclization gave a single isomer, however, also with the undesired $Z$-geometry. With $5 \mathrm{~mol} \%$ Grubbs 2nd-generation catalyst, the yield was unstable ranging from trace to $45 \%$. A higher amount of catalyst $(60 \mathrm{~mol} \%$ ) was necessary to obtain reproducible results (53\%). Due to the low efficiency of this key reaction, they later changed to another strategy to complete the total synthesis (vide infra).

In 2008, Panek and co-workers achieved the third total synthesis of 1. ${ }^{25,26}$ Their key macrocyclization (Scheme 7) was an intramolecular Barbier-type organometallic addition (Williams and Shamim ${ }^{27}$ seemingly also intended to apply a Barbier-type reaction for macrocyclization though at $\mathrm{C} 4 \mathrm{a}-\mathrm{C} 5$ bond of kendomycin. However no further report was published) with substrate 37 using freshly prepared $\mathrm{SmI}_{2}$ in tetrahydrofuran. The C19-C20 single bond connected highly selectively, providing a single diastereomer 38 in modest $60 \%$ yield. Subsequently, three steps furnished the final target $\mathbf{1}$.

Later in 2008, Rychnovsky and co-workers reported their formal total synthesis of $1 .{ }^{28}$ Actually, in 2006, they published an early formal total synthesis of $\mathbf{1}$ with Prins tetrahydropyran cyclization to a Smith's intermediate that was ahead of the key macrocyclization step. ${ }^{29}$ In the 2008 paper, the Rychnovsky group applied Prins reaction to the macrocyclization step (Scheme 8). Under acetic acid and $\mathrm{BF}_{3} \cdot \mathrm{OEt}_{2}$ conditions, the $\mathrm{C} 9-\mathrm{OH}$ and C5-aldehyde of compound 39 first intramolecularly linked to form an oxocarbenium ion 40. Then, Prins

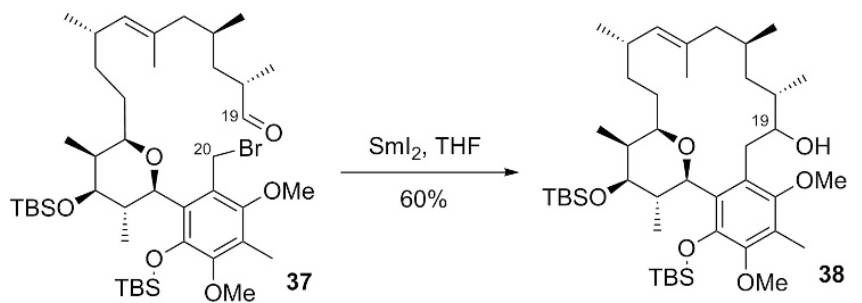

Scheme 7 The Panek group's Barbier-type macrocyclization between C19 and $\mathrm{C} 2 \mathrm{O}$. THF, tetrahydrofuran. reaction between $\mathrm{C} 5$ and $\mathrm{C} 6$ followed by an acetate trap afforded the desired product 41 (33\%) together with the fluoride-trapped byproduct 42 (48\%). Though minimization of the amount of 42 failed under other conditions, this reaction is still a very efficient transformation-highly selectively constructing C5, C6 and C7 (three) stereogenic centers, one tetrahydropyran ring and one macrocyclic ring in one step. Subsequent removal of the acetate and sulfonyl protecting groups provided the Lee group's intermediate 43 , thereby achieving a formal total synthesis of 1 .

Despite the failure of macrocyclization at the C13-C14 double bond by the RCM and Horner-Wadsworth-Emmons strategies (vide supra), Mulzer and co-workers persisted in their pursuit of total synthesis of 1 at different cyclization sites. In 2009, they disclosed two distinct total synthesis routes. ${ }^{30,31}$ One was based on their long-time RCM assumption, but at other disconnection sites than C13-C14 (Scheme 9). They first prepared substrate 44, its C5-epimer 45, and its C5-ketone analog 46 to test RCM between C9 and C10. While 45 and 46 yielded no cyclization products, 44 did macrocyclize and afford 47 in $46 \%$ yield. However, 47 could not undergo the subsequent tetrahydropyran formation under various conditions such as iodination, oxymercuration or selenocyclization. Although there would have been additional options (for example, Mitsunobu inversion at $\mathrm{C} 5-\mathrm{OH})$, they abandoned the $\mathrm{C} 9-\mathrm{C} 10$ disconnection approach at this point ${ }^{12}$ and turned to pursue the possibility of RCM between $\mathrm{C} 19$ and C20. However, after the preparation of segments 49 and 50, it was found to be impossible to connect them together to afford the RCM precursor 51. Thus, their choice was changed once again to another disconnection site between $\mathrm{C} 11$ and $\mathrm{C} 12$. In this case, with Grubbs 2nd-generation catalyst, the prepared substrate $\mathbf{5 3}$ (7:2 epimer mixture at C5) efficiently provided the macrocyclic product 54 in $62 \%$ yield as the single $E$-isomer (only the major epimer cyclized). Subsequent hydrogenation of the newly formed double bond and tetrahydropyran cyclization under acidic condition afforded the Lee group's intermediate $\mathbf{4 3}$. Alternatively, $\mathbf{4 3}$ could also be synthesized from 53 through a more efficient sequence (tetrahydropyran cyclization, RCM and then hydrogenation). The Mulzer group further developed a shorter route to achieve the total synthesis of $\mathbf{1}$ from $\mathbf{4 3}$. In the same paper, the Mulzer group reported another novel strategy from seco acid 57 via Keck macrolaztonization/photo-Fries

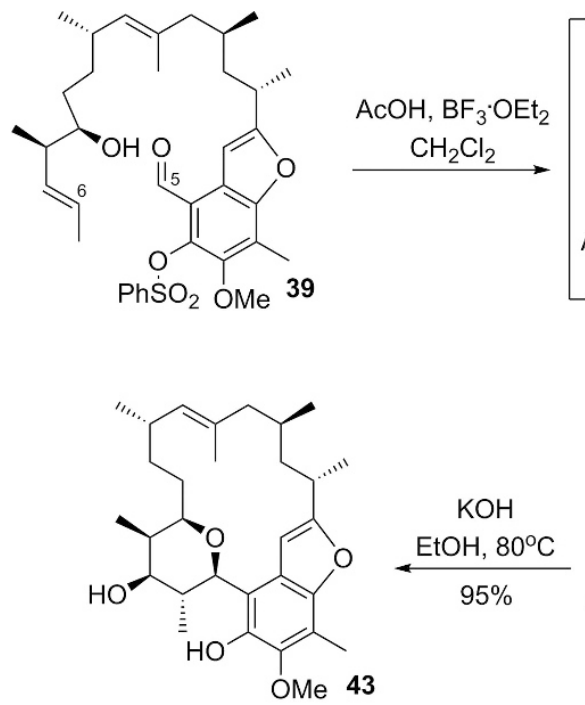

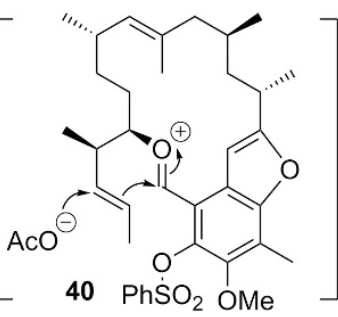
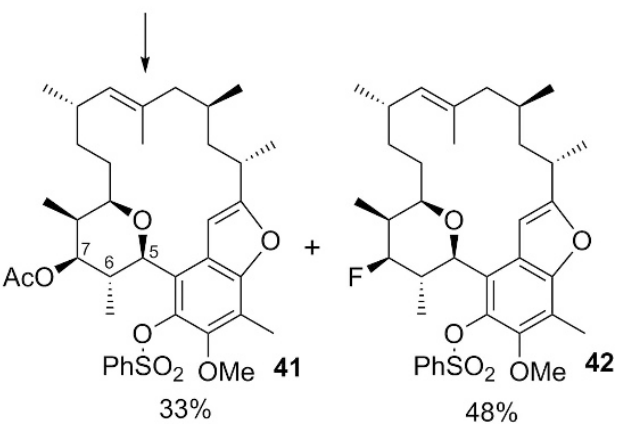

Scheme 8 The Rychnovsky group's macrocyclization using Prins reaction. Ph, phenyl. 


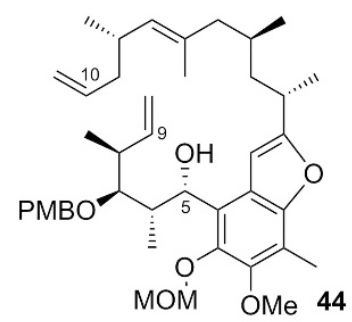

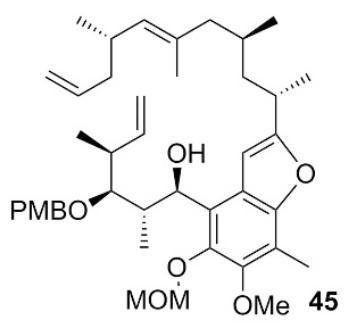

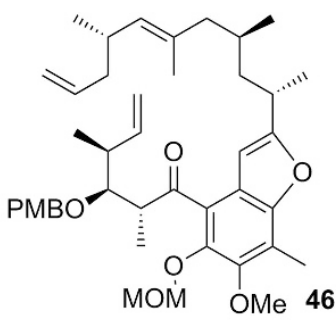

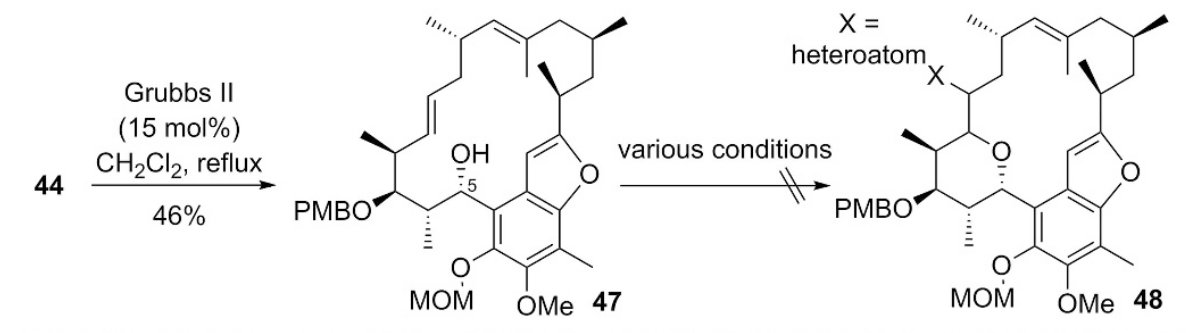

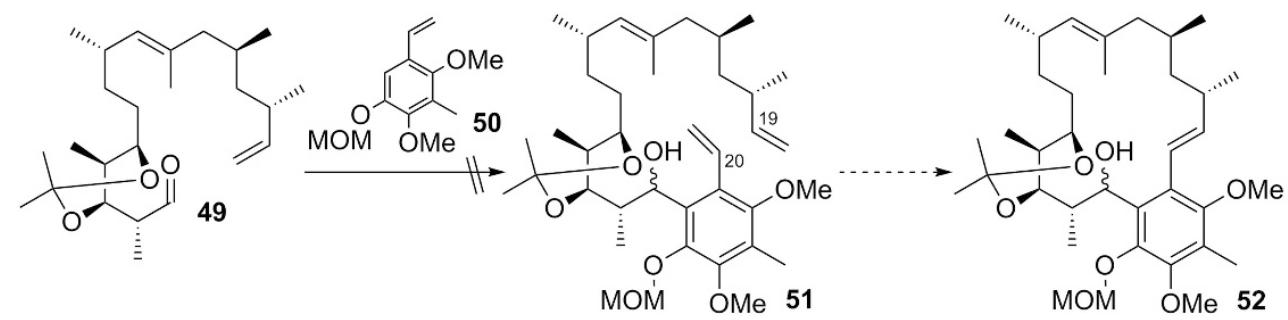

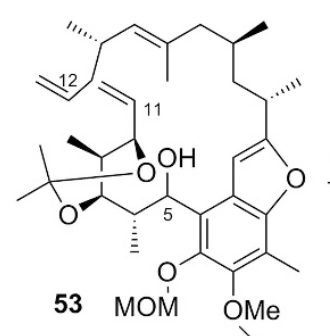

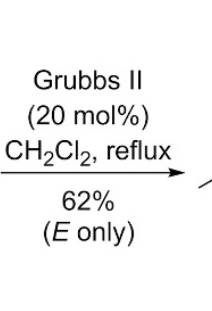<smiles>CC=CC(C)C=C(C)CC(C)CCC</smiles>

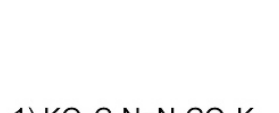
1) $\mathrm{KO}_{2} \mathrm{C}-\mathrm{N}=\mathrm{N}-\mathrm{CO}_{2} \mathrm{~K}$<smiles>COc1c(O)c([C@H]2CC(CCC(C)C=C(C)CC(C)C)OC(C)C2C)c2cc([C@@H](C)CC(C)C)oc2c1O</smiles>

$\mathrm{HCl}, 71 \%$

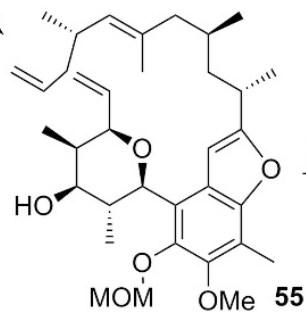

Grubbs II (20 $\mathrm{mol} \%)$ $\stackrel{\mathrm{CH}_{2} \mathrm{Cl}_{2} \text {, reflux }}{\longrightarrow}$ $(E: Z=15: 1)$<smiles>COc1c(OC)c(C)c2occc2c1[C@H]1OC[C@@H](C)[C@H](O)[C@H]1C</smiles>
MOM OMe 54 $\mathrm{KO}_{2} \mathrm{C}-\mathrm{N}=\mathrm{N}-\mathrm{CO}_{2} \mathrm{~K}$<smiles>COc1c(OC)c(C)c2oc([13CH3])cc2c1[C@@H]1O[C@H](/C=C/[C@H](C)/C=C(\C)CC(C)C)[C@H](C)[C@H](O)[C@H]1C</smiles>

Scheme 9 The Mulzer group's macrocyclization attempts using RCM at connection sites other than C13-C14. PMB, p-methoxybenzyl.

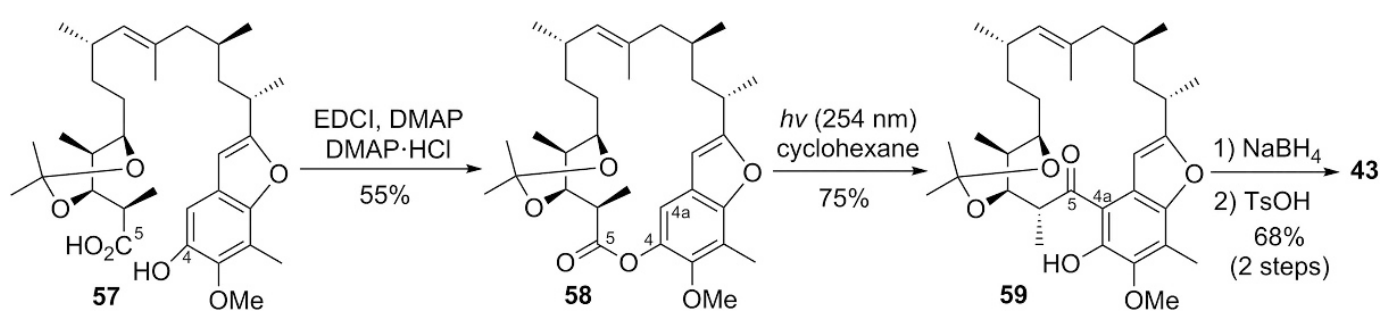

Scheme 10 The Mulzer group's macrocyclization using Keck lactonization/photo-Fries rearrangement strategy. EDCl, $N$-ethyl- $N$ '-(3-dimethylaminopropyl) carbodiimide hydrochloride; DMAP, 4-dimethylaminopyridine; Ts, $p$-toluenesulfonyl. 
<smiles>[C-]#COC1C(C)C(C#C)OC(CCC(C)C=C(C)CC(C)CC(C)C(=C)CO)C1C</smiles>

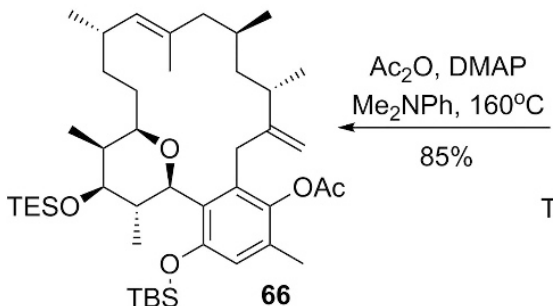

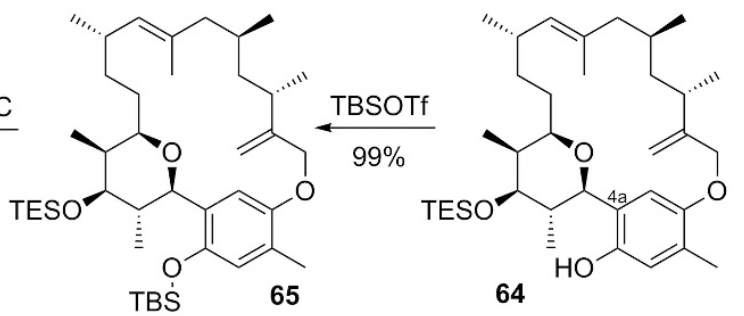

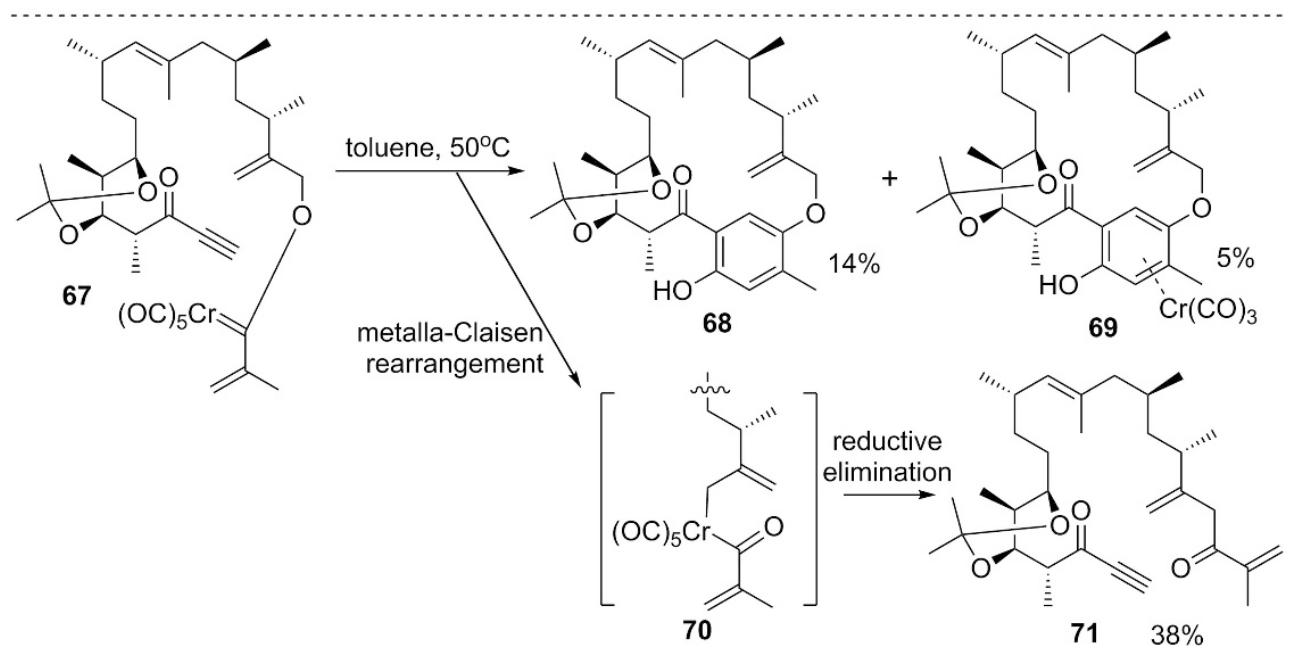

Scheme 11 The Nakata and Saikawa group's construction of the macrocarbocycle using Dötz benzannulation and Claisen rearrangement.<smiles>[2H]c1c(C2OC(CCC(C)C=C(C)CC(C)CC(C)C(=O)OOCC(=C)C(C)C)C(C)C(OC(C)C)C2C)cc(O)c(C)c1OC</smiles>

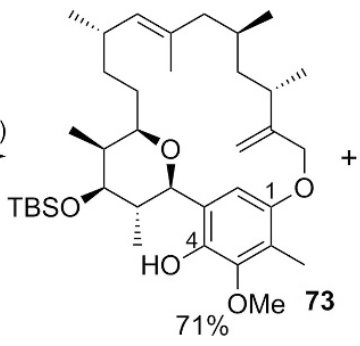

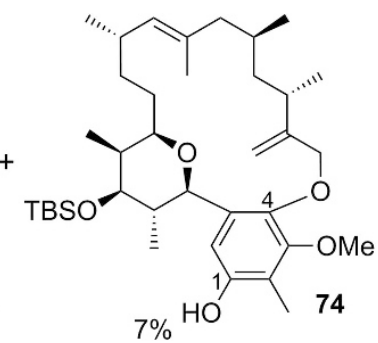<smiles>C=C(Cc1c(O)c(C)c(O[18O])c([18OH])c1C1OC(CCC(C)C=C(C)CC(C)C)C(C)C(C)C1OC(C)(C)C)CC(C)C</smiles><smiles>CCCCCCCCCNCC</smiles>

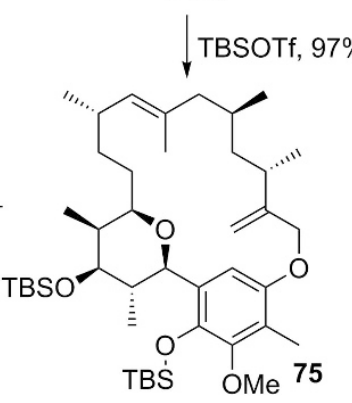

Scheme 12 The Arimoto group's construction of the macrocarbocycle with Tsuji-Trost macroetherification and Claisen rearrangement. $\mathrm{dba}$, dibenzylideneacetone. 

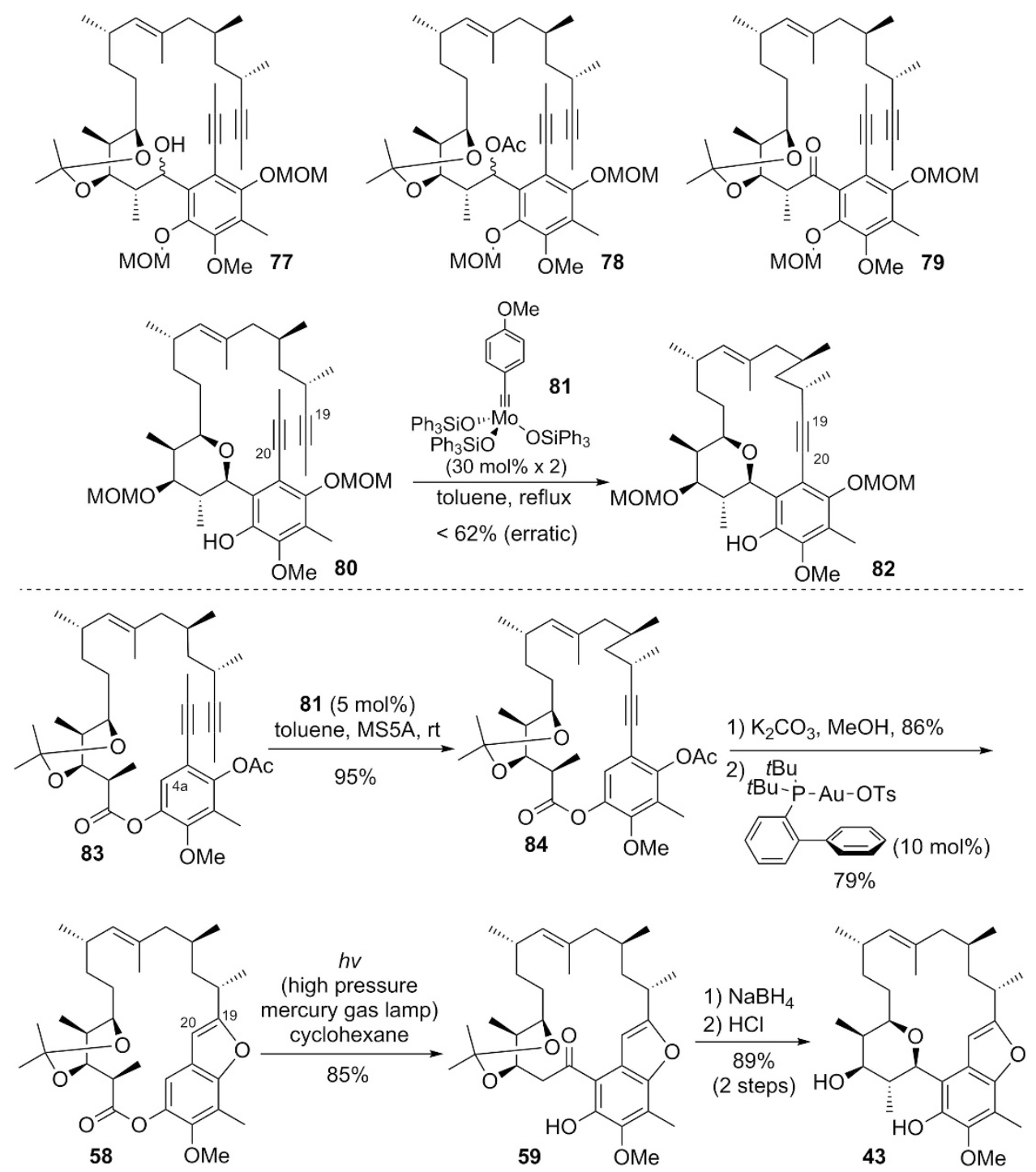

Scheme 13 The Fürstner group's construction of the macrocarbocycle with ring-closing alkyne metathesis between C19 and C20. MS, molecular shieves.

rearrangement sequence affording cleanly compound $\mathbf{5 9}$, which was further transformed to the same key intermediate 43 after two steps (Scheme 10).

In 2010, another novel total synthesis of $\mathbf{1}$ was reported by Nakata, Saikawa, and co-workers using a key intramolecular Dötz benzannulation and Claisen rearrangement to construct the macrocycle (Scheme 11). ${ }^{32,33}$ Actually, among kendomycin synthetic studies, White et al. ${ }^{34}$ first introduced an intermolecular Dötz benzannulation to construct the aromatic ring, though they encountered great problems in the later macrocyclization step. ${ }^{35}$ Instead, the Nakata and Saikawa group elegantly designed a different type of Fisher carbene substrate $\mathbf{6 2}$ (easily prepared from tetrahydropyran alkyne 60) and applied it to an intramolecular Dötz benzannulation, which could simultaneously construct the macrocycle. The desired ansa-product $\mathbf{6 4}$ formed smoothly and was obtained as the sole isolated product in modest yield. After TBS protection, using $\mathrm{Ac}_{2} \mathrm{O}$ to in situ trap the newly generated phenol in the $N$, $\mathrm{N}$-dimethylaniline solvent, the thermal Claisen rearrangement constructed the macrocarbocycle 66 highly efficiently with $85 \%$ yield from the oxa-metacyclophane 65 . With the TBS analog of 60 , the Nakata and Saikawa group also obtained the related derivative of 66 with similar efficiency. Several additional steps completed the total synthesis of 1. Interestingly, the Nakata and Saikawa group reported the Dötz benzannulation of substrate $\mathbf{6 7}$ without the tetrahydropyran ring, providing the desired 68 in only $14 \%$ yield along with considerable amount of byproduct 71 (38\%), which was formed by a metalla-Claisen-type rearrangement of the carbene complex to generate $\mathbf{7 0}$, followed by reductive elimination.

In 2014, Arimoto and co-workers achieved their total synthesis of $1 .{ }^{36}$ Unsatisfied with their previous RCM strategy at C13-C14 (vide supra), this time they changed the key reaction to a Pd-catalyzed Tsuji-Trost macro-etherification on hydroquinone 72 (Scheme 12). The yield of the desired $\mathrm{C} 1-\mathrm{O}$-tethered product 73 and its regioselectivity over the C4-O-tethered byproduct 74 were found to be highly sensitive to the reaction conditions. Extensive studies finally provided 73 in $71 \%$ isolated yield (10:1 ratio to 74 ). Subsequent TBS protection gave 75 , which afforded the Claisen rearrangement product 76 in almost quantitative yield under their previous developed condition. ${ }^{24}$ Several more steps from 76 accomplished the total synthesis of 1 .

In 2014, Fürstner and co-workers reported a formal total synthesis of 1 (Scheme 13)..$^{37}$ Their key macrocyclizaton step was a ring-closing 


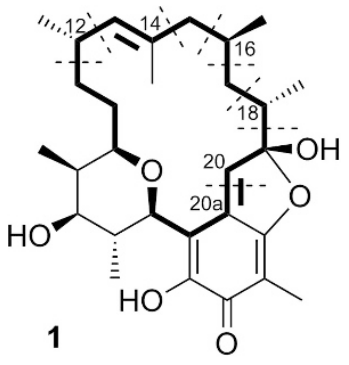

Figure 2 Unexplored retrosynthetic disconnetion sites in the macrocyclization step in kendomycin (1) syntheses.

alkyne metathesis to form a C19-C20 triple bond, which readily favored the benzofuran construction. The ring-closing alkyne metathesis trails on substrates $\mathbf{7 7 - 8 0}$ were as troublesome as they expected. Only $\mathbf{8 0}$ gave the desired product, yet with high load of the expensive catalyst $\mathbf{8 1}$ and modest erratic yield. The steric bulkiness of both the catalyst and C20 position of 77-80 was inferred to be the major cause. Thus, the relatively loose $\mathrm{C} 4 \mathrm{a}$-unsubstituted diyne $\mathbf{8 3}$ was applied, and the ring-closing alkyne metathesis proceeded exceptionally easily, furnishing the desired product $\mathbf{8 4}$ at ambient temperature in essentially quantitative and well-reproducible yield with $5 \mathrm{~mol} \%$ catalyst 81. Subsequent deprotection and Au-catalyzed hydroalkoxylation established the benzofuran $\mathbf{5 8}$, which was the same as the intermediate of the Mulzer group's photo-Fries strategy.

\section{CONCLUDING REMARKS}

For the syntheses of macrocycle natural products, the choice of tactics for the cyclization step, which often defines the overall efficiency of the total synthesis, is the key in synthetic strategies. ${ }^{38}$ For the synthesis of macrocycles larger than 12-membered rings, there are two basic strategies: direct cyclization and the cyclization-ring contraction sequence. Construction of a larger macro-heterocycle followed by a ring contraction to the desired macrocarbocycle is traditionally the popular approach via a circuitous route because a carbon-carbon bond formation is generally more difficult than a carbon-heteroatom bond formation. However, with the rapid development of synthetic methodology for carbon-carbon bond connections, direct macrocyclization to construct carbon-carbon bonds is the current trend of the field.

From information gleaned in the previous sections, readers can obtain insights for alternative macrocyclization strategies for kendomycin. To establish efficient total syntheses, all of the research groups initially attempted the macrocyclization by carbon-carbon bond formation. The early five total/formal syntheses from the Lee, Smith, Panek, Rychovsky, and Mulzer groups all adopted direct cyclization with carbon-carbon bond connection (notwithstanding a definite ring contraction through $\mathrm{O}$-glycosidation of an intermediate, the Lee group's cyclization was efficiently achieved in one pot). However, those strategies suffered from unstable/unsatisfactory yields or needed further steps to modify the connected bond (Z/E isomerization in the Smith synthesis; olefin saturation in the Mulzer synthesis). Interestingly, after the Mulzer's synthesis using Fries-rearrangement strategy, all later successful syntheses included a ring contraction step in their macrocycle syntheses. Although the combined yields were still not satisfactory for some of the attempts, the most recent strategy from the Fürstner group was truly efficient with $95 \%$ yield of ring-closing alkyne metathesis heterocycle formation and $85 \%$ yield of Fries-rearrangement contraction. Actually, several groups including ours (unpublished) used simplified model compounds to verify their strategies for macrocyclization, however, the conditions that worked for the model compounds frequently had serious difficulties when applied to the actual intermediate and needed further optimization. Nevertheless, the strategic changes in kendomycin total syntheses from direct cyclization in the earlier studies to traditional ring contraction illustrate that the modern synthetic methodology is still far from perfection.

Another factor in strategy design is the selectivity, especially diastereoselectivity, for complex natural products. While the construction of a series of stereogenic centers in linear precursor molecules is not a significant problem for modern synthetic chemistry, achieving diastereo-control during macrocyclization is not trivial. To avoid this challenge, the retrosynthetic analyses of macrocycles usually disconnect a bond not neighboring to chiral carbons, and set forth all chirality well in the macrocyclization substrates. Moreover, in the kendomycin structure, the northern part is structurally simpler and sterically less hindered compared to the heavily functionalized southern part. Therefore, it is not surprising that the initial cyclizations were tried between the $\mathrm{C} 13-\mathrm{C} 14$ bond by many research groups. However, the unsatisfactory experimental results at this position made the retrosynthetic design switch to the disconnection in the southern part. The syntheses of the Lee and Rychnovsky groups were efficient in terms of stereoselectivity in the macrocyclization, though with unstable or low yields. Particularly, the latter successfully established three stereogenic centers simultaneously. Cyclization used by other groups did not have selectivity problems, except for regiocontrol in Arimoto's Tsuji-Trost macroetherifcation strategy. Notably, the Mulzer group successfully developed a highly diastereoselective construction of $\mathrm{C} 5$ after the macrocyclization.

Figure 2 summarizes the yet unexplored (or failed) potential macrocyclization sites in kendomycin (1). For C11-C12, C12-C13, C15-C16, C16-C17, C17-C18, and C18-C19 bonds, connection of these bonds needs to control a heteroatom-free chiral carbon diastereoselectivity, and thus, macrocyclization at those positions seems really difficult. However, a challenge in highly efficient cyclization might be the future direction of kendomycin synthesis. The C14-C15 bond, at which cyclization might be achieved by intramolecular cross-coupling, has also not been examined. Another attractive possible cyclization is at the $\mathrm{C} 20-\mathrm{C} 20 \mathrm{a}$ bond via a biomimetic aldol reaction on quinone substrates.

Extensive structure-activity relationship studies for $\mathbf{1}$ have not been reported to date. ${ }^{4,7,8,33}$ However, the results of the Nakata and Saikawa group suggested that the ansa-macrocyclic skeleton is essential for its antimicrobial activity. ${ }^{33}$ Therefore, the macrocyclization step is unavoidable for the future structure-activity relationship studies and should be thought and designed for more convenient preparation of structure-activity relationship libraries.

Thus far, the reported total and formal total syntheses of $\mathbf{1}$ are all from long-standing groups in the total synthesis field. It is predictable that with the large growth of kendomycin research, more groups in synthetic methodology and medicinal chemistry will join the field and develop more efficient synthetic pathways to $\mathbf{1}$.

\section{CONFLICT OF INTEREST}

The authors declare no conflict of interest.

\section{ACKNOWLEDGEMENTS}

We are grateful for the financial support of Grants-in-Aid for Scientific Research (nos.18032010 and 21310136) from the JSPS. 
1 Funahashi, Y., Kawamura, N. \& Ishimaru, T. Endothelin receptor antagonists manufacture. JP08231551. Chem. Abstr. 126, 6553 (1996).

2 Funahashi, Y., Ishimaru, T. \& Kawamura, N. Endothelin receptor antagonists manufacture. JP08231552. Chem. Abstr. 125, 326518 (1996).

3 Su, M. H., Hosken, M. I., Hotovec, B. J. \& Johnston, T. L. Antiosteoporotic compound. US5728727. Chem. Abstr. 128, 239489 (1998).

4 Bode, H. B. \& Zeeck, A. Structure and biosynthesis of kendomycin, a carbocyclic ansa-compound from Streptomyces. J. Chem. Soc., Perkin Trans. 1, 323-328 (2000).

5 Elnakady, Y. A. et al. Evidence for the mode of action of the highly cytotoxic Streptomyces polyketide kendomycin. Chembiochem. 8, 1261-1272 (2007).

6 Beck, P. et al. Interactions of the natural product kendomycin and the $20 \mathrm{~S}$ proteasome. J. Mol. Biol. 426, 3108-3117 (2014).

7 Janssen, C. O. et al. Interaction of kendomycin and semi-synthetic analogues with the anti-apoptotic protein Bcl-xl. Bioorg. Med. Chem. Lett. 18, 5771-5773 (2008).

8 Bode, H. B. \& Zeeck, A. Biosynthesis of kendomycin: origin of the oxygen atoms and further investigations. J. Chem. Soc., Perkin Trans. 1, 2665-2670 (2000).

9 Wenzel, S. C., Bode, H. B., Kochems, I. \& Müller, R. A type I/type III polyketide synthase hybrid biosynthetic pathway for the structurally unique ansa compound kendomycin. Chembiochem. 9, 2711-2721 (2008).

10 Shan, M., Wang, L., Zhang, Q. \& O'Dooherty, G. A. Tactics in total synthesis of (-)-kendomycin. Chemtracts 22, 1-17 (2009).

11 Martin, H. J., Magauer, T. \& Mulzer, J. In pursuit of a competitive target: total synthesis of the antibiotic kendomycin. Angew. Chem. Int. Ed. 49, 5614-5626 (2010).

12 Martin, H. J., Magauer, T. \& Mulzer, J. In pursuit of an elusive target: our kendomycin story. Strategies Tactics Org. Synth. 8, 261-289 (2012).

13 Saikawa, Y., Tanaka, K. \& Nakata, M. Construction of ansa-skeleton via intramolecular Dötz benzannulation: total synthesis of kendomycin. Yuki Gosei Kagaku Kyokaishi 72, 1143-1153 (2014).

14 Bicchielli, D. et al. Olefin metathesis as key step in the synthesis of bioactive compounds: challenges in the total synthesis of (-)-kendomycin. Curr. Org. Synth. 9, 397-405 (2012).

15 Mulzer, J., Pichlmair, S., Green, M. P., Marques, M. M. B. \& Martin, H. J. Toward the synthesis of the carbacylic ansa antibiotic kendomycin. Proc. Natl Acad. Sci. USA 101, 11980-11985 (2004).

16 Martin, H. J., Drescher, M., Kählig, H., Schneider, S. \& Mulzer, J. Synthesis of the $\mathrm{C} 1-\mathrm{C} 13$ fragment of kendomycin: atropisomerism around a $\mathrm{C}$-aryl glycosidic bond. Angew. Chem. Int. Ed. 40, 3186-3188 (2001).

17 Marques, M. M. B., Pichlmair, S., Martin, H. J. \& Mulzer, J. Stereocontrolled synthesis of $C$-arylglycosides applied to the south west fragment of the antibiotic kendomycin. Synthesis 34, 2766-2770 (2002).

18 Pichlmair, S., Marques, M. M. B., Green, M. P., Martin, H. J. \& Mulzer, J. A novel approach toward the synthesis of kendomycin: selective synthesis of a $C$-aryl glycoside as a single atropisomer. Org. Lett. 5, 4657-4659 (2003).
19 Green, M. P. et al. Synthesis of analogue structures of the $p$-quinone methide moiety of kendomycin. Org. Lett. 6, 3131-3134 (2004).

20 Yuan, Y., Men, H. \& Lee, C. Total synthesis of kendomycin: a macro-C-glycosidation approach. J. Am. Chem. Soc. 126, 14720-14721 (2004).

21 Smith, A. B. III, Mesaros, E. F. \& Meyer, E. A. Total synthesis of (-)-kendomycin exploiting a Petasis-Ferrier rearrangement/ring-closing olefin metathesis synthetic strategy. J. Am. Chem. Soc. 127, 6948-6949 (2005).

22 Smith, A. B. III, Mesaros, E. F. \& Meyer, E. A. Evolution of a total synthesis of (-)-kendomycin exploiting a Petasis-Ferrier rearrangement/ring-closing olefin metathesis strategy. J. Am. Chem. Soc. 128, 5292-5299 (2006).

23 Sengoku, T., Uemura, D. \& Arimoto, H. Ring-closing metathesis approach to a 16-membered macrocycle of kendomycin. Chem. Lett. 36, 726-727 (2007).

24 Sengoku, T., Arimoto, H. \& Uemura, D. Synthetic approach to kendomycin: preparation of the C-glycosidic core. Chem. Commun. 40, 1220-1221 (2004).

25 Lowe, J. T. \& Panek, J. S. Total synthesis of (-)-kendomycin. Org. Lett. 10, 3813-3816 (2008).

26 Lowe, J. T. \& Panek, J. S. Stereocontrolled [4+2]-annulation accessing dihydropyrans: synthesis of the C1a-C10 fragment of kendomycin. Org. Lett. 7, 1529-1532 (2005).

27 Williams, D. R. \& Shamim, K. Efforts toward the total synthesis of (-)-kendomycin. Org. Lett. 7, 4161-4164 (2005).

28 Bahnck, K. B. \& Rychnovsky, S. D. Formal synthesis of (-)-kendomycin featuring a Prins-cyclization to construct the macrocycle. J. Am. Chem. Soc. 130, 13177-13181 (2008).

29 Bahnck, K. B. \& Rychnovsky, S. D. Rapid stereocontrolled assembly of the fully substituted $C$-aryl glycoside of kendomycin with a Prins cyclization: a formal synthesis. Chem. Commun. 42, 2388-2390 (2006).

30 Magauer, T., Martin, H. J. \& Mulzer, J. Total synthesis of the antibiotic kendomycin by macrocyclization using photo-Fries rearrangement and ring-closing metathesis. Angew. Chem. Int. Ed. 48, 6032-6036 (2009).

31 Magauer, T., Martin, H. J. \& Mulzer, J. Ring-closing metathesis and photo-Fries reaction for the construction of the ansamycin antibiotic kendomycin: development of a protecting group free oxidative endgame. Chem. Eur. J. 16, 507-519 (2010).

32 Tanaka, K. et al. Total synthesis of kendomycin featuring intramolecular Dötz benzannulation. Org. Lett. 12, 1700-1703 (2010).

33 Tanaka, K. et al. Synthesis and biological evaluation of kendomycin and its analogues. J. Org. Chem. 79, 9922-9947 (2014).

34 White, J. D. \& Smits, H. Application of the Dötz reaction to Construction of a major portion of the ansa macrocycle (-)-kendomycin. Org. Lett. 7, 235-238 (2005).

35 Smits, H. Studies towards the total synthesis of (-)-kendomycin (PhD thesis, Oregon State University). Chem. Abstr. 148, 144520 (1998).

36 Sengoku, T. et al. Total synthesis of the antibiotic kendomycin: a macrocyclization using the Tsuji-Trost etherification. Angew. Chem. Int. Ed. 53, 4213-4216 (2014).

37 Hoffmeister, L., Persich, P. \& Fürstner, A. Formal total synthesis of kendomycin by way of alkyne metathesis/gold catalysis. Chem. Eur. J. 20, 4396-4402 (2014).

38 Gulder, T. \& Baran, P. S. Strained cyclophane natural products: macrocyclization at its limits. Nat. Prod. Rep. 29, 899-934 (2012). 